\title{
CONTORNOS ATUAIS DA EUTANÁSIA E DA ORTOTANÁSIA: BIOÉTICA E BIODIREITO. A NECESSIDADE DO CONTROLE SOCIAL DAS TÉCNICAS MÉDICAS
}

\author{
Maria Celeste Cordeiro Leite Santos \\ Professora Associada do Departamento de Filosofia e \\ Teoria Geral do Direito da Faculdade de Direito da \\ Universidade de São Paulo
}

\begin{abstract}
Resumo:
A tecnociência está presente em nosso cotidiano e insinua-se em nossa maneira de pensar, de dar a vida (Fertilização in vitro) ou administrar a morte (tanatotecnologia). Nesta lógica, o tradicional princípio da indisponibilidade do ser humano vem sendo substituído por uma forma mais ampla, pelo princípio oposto da disponibilidade no interesse da comunidade e por "razões" de Estado.

A reforma do Código Penal em seu anteprojeto de lei cuída da eutanásia, especificamente no art. $121 \S 3^{\circ}$, da ortotanásia no $\S 4^{\circ}$ como causa de exclusão da ilicitude. Críticas e sugestões são por nós apresentadas.
\end{abstract}

Abstract:

The technoscience is present in our quotidian and makes advances in our way of thinking, of giving the life (Fertilization in vitro) or to administer the death (thanatechnology). In this logic, the traditional principle of inalienably of the human being has been substituted by a wider form, for the opposite principle of the alienably in the community's interest and for "reasons" of State.

The reform of the Penal Code in your law project takes care of the euthanasia, specifically in the art. $121 \S 3^{\circ}$. of the orthotanasia in $\S 4^{\circ}$ as cause of exclusion of the illicitness. Critics and suggestions are for us presented.

Unitermos: ortotanásia; bioética; eutanásia.

1. Introdução

A experimentação humana e as técnicas de engenharia genética configuram um novo domínio peculiar do conhecimento sobre o qual versa uma nova ciência: a Bioética. Seu objetivo é trazer critérios éticos e morais à 
investigadores e profissionais, propondo limites ao técnico e científico no sentido de que a dignidade e a vida humana seja um prius sobre qualquer outro valor.

Todavia, isto não-basta. Os princípios éticos esgotam sua operatividade no plano interno da consciência pessoal. É necessário um instrumento de controle social e institucional. Um novo âmbito do dever ser em que se regulem as relações intersubjetivas à luz dos princípios da Bioética: nasce um novo ramo do Direito, o Biodireito (Biojuris). Vila-coro o define como: "(...) a Ciência que tem por objeto a fundamentação e pertinência das normas jurídico-positivas de "lege ferenda" e de "lege lata" para lograr e verificar sua adequação aos princípios e valores da Ética em relação à vida humana, isto é, sua adequação aos valores da Bioética"

O objeto da nova Ciência é o homem como sui iuris e compreende entre outras coisas a regulamentação da Biotecnologia e de seus resultados: reprodução assistida, manipulação de gens, embriões e fetos humanos, as intervenções que afetam ao direito à liberdade e identidade do indivíduo e da espécie humana (como a clonagem, os bíblidos), questões como a eutanásia, ortotanásia, transplante de órgãos, etc. Em realidade tanto a Bioética quanto o Biodireito respondem aos posicionamentos clássicos do pensamento moral kantiano. Recuperase a dimensão que o filósofo atribuiu à oposição entre pessoa e coisa. Da argumentação kantiana se infere a condenação prévia de toda instrumentação biomédica do homem, que "não pode ser utilizado por nenhum outro homem como simples meio" A moral kantiana estabelece a justificação para exigir o consentimento informado e livre, rechaçando toda redução do ser e corpo humano a mera categoria de coisas.

"Suposto que exista algo cuja existência tenha em si mesma um valor absoluto, algo que como fim em si, possa ser um princípio de leis determinadas, é para ele, e só nele que se falaria de um imperativo categórico. O homem existe como fim em si, e por conseguinte limita toda a faculdade de agir como nos pareça, por ser objeto de respeito"

Porém, existe um regime jurídico geral, sistemático e coerente de por ex.: a ortotanásia e a eutanásia? Não no âmbito internacional. Não no plano comunitário. Dificilmente no Direito brasileiro. E, desde logo, os três níveis se afastam de compor um conjunto integral e integrado.

O art. 121 do anteprojeto de lei do novo Código Penal brasileiro em seu $\S 3^{\circ}$ cuida expressamente da eutanásia que, anteriormente era tratada, 
jurisprudencial e doutrinariamente como homicídio privilegiado (como relevante valor moral ou social, conforme o caso específico).

\begin{tabular}{|l|l|}
\hline Anteprojeto & Código atual e legislação extravagante \\
\hline $\begin{array}{l}\text { Eutanásia } \\
\text { Art. } 121(. . .)\end{array}$ & não há previsão específica. \\
$\S 3^{\circ}$ Se o autor do crime é cônjuge, & \\
companheiro & \\
descendente, irmão ou pessoa ligada & \\
por estreitos laços de afeição à vítima & \\
e agiu por compaixão, a pedido desta & \\
imputável e maior, de dezoito anos, & \\
para abreviar-lhe sofrimento físico & \\
insuportável, em razão de doença & \\
grave e em estado terminal, \\
devidamente diagnosticado. Pena- \\
reclusão de dois a cinco anos.
\end{tabular}

Ressalta-se, entretanto, que a proposta de reforma não-constitui, como aconselha a melhor técnica legislativa, um tipo penal autônomo, preferindo incluir a hipótese legal no $\S 3^{\circ}$ No relatório que precede o texto da Reforma, a Comissão, ao afirmar que se encontra sensível às circunstancias, e visando individualizar a pena "sugere explicitar a eutanásia tomando-a como causa de diminuição de pena (...)" parece merecer a hipótese legal um tipo de homicídio privilegiado autônomo e não causa de simples diminuição de pena. Tanto assim o é que, em seguida, no $\S 4^{\circ}$ a Comissão admite, conforme defendido em tese por esta autora, a denominada ortotanásia forma característica de eutanásia.

Uma rigorosa adequação jurídica se faz necessária. Não-basta que na eutanásia (vocábulo derivado do grego "eu" bem e "thanasia" morte tranquilla, sem dor, sem sofrimento) se cuide de doença grave. É mister tratar-se de doença grave, incurável e terminal. Cabe, porém, perguntar: o que é "doença grave"? Seria a doença em evolução, ou seqüela de uma doença? 
No que se refere à causa de exclusão da ilicitude

\begin{tabular}{|l|l|}
\hline Anteprojeto & Código atual \\
\hline Diminuição de pena art. 121 & Caso de diminuição de pena \\
$\S 4^{\circ}$ Não constitui crime deixar de & $\S 1^{\circ}$ Se o agente comete crime impelido \\
manter a vida de alguém por meio & por motivo de relevante valor social ou \\
artificial se previamente atestado por 2 & moral, ou sob domínio de violenta \\
médicos, a morte como iminente e & emoção, logo em seguida a injusta \\
inevitável e desde que haja & provocação da vítima, o juiz pode \\
consentimento do paciente, ou na sua & reduzir a pena de um sexto a um terço. \\
impossibilidade, de ascendente, & \\
descendente, cônjuge, companheiro ou & \\
irmão. & \\
\hline
\end{tabular}

A figura corresponde à chamada "eutanásia por omissão" "ortotanásia" "paraeutanásia" Uma forma mais explicativa dos termos consistiria no auxílio médico à morte, que se traduz precisamente na ajuda dada pelo médico ao processo natural de morte. Também chamada "mercy killing" "letting die" pela literatura anglo-saxônica.

Compreende-se aqui, também, o denominado "excesso terapêutico" em casos da denominada morte encefálica, que não pode ser confundida em momento algum com a morte cerebral.

Importantes fatores entram nos conceitos aventados. O primeiro é representado pela intenção de quem produz ou omite prevenir a morte. Interesse, também, reveste o meio empregado, que deve ser indolor. Sendo pressuposto do ato eutanásico a cessação do sofrimento, nem sempre se pode falar que este seja evidente (como dor consciente, agonia mental e grave invalidade física). Por exemplo: quando em caso de coma prolongado o paciente não está consciente, não se pode dizer que esteja sofrendo.

Deve ser incluído, no rol de requisitos autorizadores, que seja praticado por médico ou ordem médica, atestada por outros dois médicos nãopertencentes à equipe de transplantes de órgãos (de conformidade com a lei de transplantes vigentes).

A distinção deve ser feita rigorosamente, sob pena de se submeterem a um denominador comum casos éticos, juridicamente muito diferentes, ainda quando 
para ambos se propugne identidade de soluções em face do Direito Penal. O único caso que se entende poder ser denominado de ortotanásia é a circunstância de o doente estar incurso já em um processo que, segundo o conhecimento humano e um juízo razoável de prognose médica, conduzirá imediatamente e sem remissão à morte. A opinião que se segue é a de que o auxílio médico à morte será lícito sempre que operado sem encurtamento do período natural de vida. Nestes casos, o médico (e só ele) não é obrigado a intervir no sentido de prolongar a vida do paciente além do período natural, salvo se tal lhe for expressamente requerido pelo doente.

Estranha-se, no que se refere ao rol das pessoas legitimadas a exarar o consentimento, na impossibilidade de o próprio paciente poder fazê-lo, que se tenha dado prioridade ao cônjuge em detrimento do companheiro. Isto porque inúmeros são os casos em que o casamento não foi formalmente desconstituído, mas qualquer de suas partes encontra-se vivendo maritalmente com outra pessoa. Além disto, há previsão constitucional no sentido de reconhecimento da união estável entre o homem e mulher como entidade familiar, para efeito de proteção do Estado (art. 226, $\S 3^{\circ}$ ), bem como recentemente foi elaborada lei que regulamenta o concubinato. Face a estes problemas, entende-se mais recomendável a substituição de "cônjuge, companheiro" por aquele que vive maritalmente com o paciente.

\section{Eutanásia e Eugenia}

O problema da definição e formas de eutanásia.

a. A palavra eutanásia, derivada dos vocábulos eu, que literalmente significa bem e thanasia (Thanatos) equivalente à morte, entre nós significa boamorte, morte tranqüila, sem dor nem sofrimento. Criada no século XVII, pelo filósofo inglês Francies Bacon (Bacon de Verulamio), em seu Novum Organum, também foi utilizado no sentido de que "o médico deve acalmar os sofrimentos $e$ as dores, não apenas quando este alívio possa trazer a cura, mas também quando pode servir para procurar uma morte doce e tranqüila" Inspirada na piedade ou compaixão pelo doente ou moribundo, não se propõe puramente a causar a morte.

b. Distanásia - ou eutanásia lenitiva consiste no emprego de meios mitigadores ou eliminadores do sofrimento. Tida como lícita por moralistas e teólogos, suscita dúvidas quando o emprego de analgésicos é feito em altas doses, 
acarretando um encurtamento da vida, não querido diretamente, mas originado por inesperada concomitância.

c. Eutanásia eugênica ou eugenia, significa a eliminação indolor dos doentes incuráveis, dos inválidos e velhos, no escopo de aliviar a sociedade do peso de pessoas economicamente inúteis.

A eutanásia e a eugenia são temas correlatos, na medida em que esta, com o pretexto de selecionar, propuser o extermínio "legal" de seres humanos.

Os autores que se ocupam do tema apontam inúmeros casos e citam costumes reinantes em certas sociedades, por meio dos quais a eutanásia eugênica era efetivada. É necessário esclarecer, porém, que a morte aí dada, com características eutanásicas, não passava de eugenia, posto que, faltava em todos os casos o consentimento das vítimas. Os hindus que atiravam no Rio Ganges os enfermos incuráveis após receberem um pouco da lama sagrada na boca e no nariz, os celtas e brâmanes que matavam ou abandonavam crianças deformadas e velhos, os espartanos que matavam os doentes, o faziam não a pedido das vítimas, mas no interesse do Estado. Essas pessoas eram um obstáculo ao enriquecimento da comunidade e uma carga inútil para os familiares. Nada havia de humanitário nesse procedimento.

A proposição de Thomas Morus, em sua obra Utopia, segundo a qual os magistrados deveriam cuidar para que os incuráveis se deixassem morrer, são práticas, na verdade, eugênicas.

A eugenia foi criada por Francis Galtón, em 1883, que definiu como "o estudo dos meios que sob o controle social podem melhorar ou deteriorar física ou intelectualmente a qualidade das raças nas gerações futuras" A eugenia resulta da pretensão estatal, que remonta à antigüidade, segundo a qual promover-se-ia a seleção e aprimoramento da espécie humana.

Posto o problema e estabelecida a distinção entre esta e a eutanásia, à luz do Direito esta deve ser encarada como crime de homicídio e, quiçá, até como modalidade qualificada desse delito. 


\section{d. Eutanásia e medicina -}

O médico francês H. Binet Sanglé, escreveu "L'art de mourir" por meio do qual elabora um projeto de criação dos "institutos de eutanásia" dirigidos por especialistas. Escudado pelo sigilo que o rodeia, formando verdadeira muralha ao seu redor, o médico, se quiser, poderá extinguir as vidas pendentes por um fio.

Durante a Segunda Guerra Mundial, em Paris, o Hospital de Orsay, mandou seus enfermeiros injetarem medicamentos mortais nos pacientes que não podiam ser removidos.

Todavia, Hipócrates sentenciava: "a ninguém darei, para agradar, remédio mortal, nem conselho que o induza à perdição"

A antecipação da morte do paciente pelo médico constitui homicídio privilegiado (art. $121, \S 1^{\circ}$ ).

O Código de Ética Médica, em seu art. $6^{\circ}$ dispõe: "o médico deve guardar absoluto respeito pela vida humana, atuando sempre em benefício do paciente. Jamais utilizará seus conhecimentos para gerar sofrimento físico ou moral, para o extermínio do ser humano ou para permitir acobertar tentativa contra sua dignidade e integridade" (Resolução CFM, n. 1.246/88).

No Capítulo IV sobre "Relação com paciente e familiares" o art. 66 prevê: "utilizar, em qualquer caso, meios destinados a abreviar a vida do paciente, ainda que a pedido deste ou de seu responsável legal"

O Código Internacional de Ética Médica, aceito pela III Assembléia Geral da Associação Médica Mundial, realizada em Londres, outubro de 1949, declara que: "o médico deve ter sempre presente o cuidado de conservar a vida humana": e que "deve ao seu paciente completa lealdade e empregar a seu favor todos os recursos da ciência" (princípio da beneficência).

3. Outro aspecto pouco tratado, proposto pelo professor Roskan da Universidade de Liège, em julho de 1950 , na $1^{\text {a }}$ Conferência Internacional de Gerontologia é o da Ortotanásia.

O penalista português Jorge Figueiredo Dias define a ortotanásia como "a circunstância do doente estar incurso já em processo que, segundo o conhecimento humano e um razoável juízo de prognose médica, conduzirá imediatamente e sem remissão à morte" 
Trata-se de um auxílio médico à morte, lícito por ter sido operado sem encurtamento do período natural de vida.

$\mathrm{O}$ médico não-pratica, mesmo solicitado, a morte piedosa. Deixa apenas de prolongar, por meios artificiais, uma vida que, além de sofrida, mostra-se irrecuperável.

É uma eutanásia por omissão, segundo o professor Lattes. O art. 13, $2^{\circ}$. do Código Penal estabelece: "a omissão é penalmente relevante, quando o emitente devia e podia agir para evitar o resultado" No caso o médico, embora omisso, não está obrigado a prolongar a morte inexorável.

O professor Lattes da Universidade de Pavia afirma: a materialidade dos fatos em tais casos é muito diversa da verdadeira eutanásia. Nesta, a morte é devida a um fato concreto executado voluntariamente pelo médico. Naquela, o curso espontâneo da enfermidade e suas complicações são alheios aos fins e iniciativas médicas: matar é distinto de deixar morrer. Baseia-se Lattes na omissão de socorro. Para que exista este crime é mister haver uma norma jurídica expressa. Assim, quando a intervenção médica não puder obter a cura do enfermo, que se ache esta além das possibilidades humanas e, se longe de aliviar-lhe, apenas proporcione-lhe mais sofrimento, não se pode afirmar o dever de prolongar essas penosas existências.

Manter uma supervivência com meios puramente artificiais se converte em ato que causa uma morte má (Lattes La buona e la mala morte). Nestes casos não existe propriamente uma omissão de socorro no sentido penal: o enfermo não necessita de socorro. Uma assistência extremada seria ineficaz para impedir a morte que se acerca. Nestes casos se fez tudo o que era possível fazer.

Para De Greef existem modalidades de eutanásia por omissão: em umas se omitem intervenções que só poderiam prolongar durante breves momentos uma existência que se extingue. Em outra, deixa-se de prestar cuidados a enfermos sem esperança cujo fim não parece iminente. E esta constitui um passo à eutanásia econômica e não-sentimental. Tal modalidade é normalmente reprovável. Para Maria Thereza Pacheco, hospices é um termo utilizado para designar "um programa médico multidisciplinar que oferece cuidados especializados para paciente terminais e suas famílias, a fim de viverem o melhor possivel o momento da morte. Ajuda no alívio de sintomas e visa conforto durante o processo global do sofrimento (físico, psicológico, espiritual, social e econômico) que sobrevém no curso da doença, morte e luto" Sua idéia é originária de Saunderes, médica britânica que se baseou nos hospícios da Idade Média, quando utilizava a palavra hospes, de origem 
latina, cujo significado é hóspede, convidado. A tradução da palavra seria hospitalar.

Para Saunderes não há razão para a indicação da eutanásia se o paciente tiver proteção contra a dor, amparo psicológico e familiar, quanto ao encarar a morte, já que esta faz parte da natureza humana.

Para Leocir Pessini, (morrer com dignidade) é preciso ajudar as pessoas a "viverem com dignidade a própria morte" Carpe Diem (agarre o dia).

Reconciliar a vida com a morte é uma incontrolável explosão de liberdade.

4. Classificação das hipóteses de incidência

A problemática da eutanásia implica muitas hipóteses de fato, dentre as quais resumimos:

a. Eutanásia genuína (Sterbebegleitung) através tanto da assistência médica e sanitária, dirigida a paliar as dores, quanto o cuidado de outras pessoas que acompanham o enfermo;

b. Eutanásia passiva, consistente na omissão de medidas que prolongam a vida no caso de pacientes terminais;

c. Eutanásia indireta, que consiste na administração de calmantes aceitando-se o possível encurtamento da vida;

d. Eutanásia ativa, como causação ativa e voluntária da morte que se realiza normalmente a pedido do paciente;

e. Auxílio ao suicídio ou suicídio assistido através da participação em homicídio alheio, que, como em casos similares de eutanásia, se realiza geralmente para pôr termo a um estado de sofrimento insuportável.

\section{Tratamento jurídico:}

a. Eutanásia genuína nesse âmbito, o ponto de vista jurídico é unânime. O paciente tem direito à assistência básica (cuidado corporal, manutenção respiratória, alimentação adequada, tratamento dos sintomas da enfermidade, etc.) ainda quando o tratamento terapêutico ou as medidas prolongadoras da vida não estejam indicadas. 
A negação de tais auxílios pode ser punível a título de lesões, ou inclusive homicídio no caso de que se produza um encurtamento da vida.

É necessário ressaltar que, quando "cuidar de (...)" significa "curar" o profissional da Saúde se encontra desarmado (...) "Tecnologia e medicina podem tornar-se fins em si mesma e a vida poderia ser preservada quando, de fato, se deveria deixar morrer"

b. Eutanásia passiva consentida concordamos que, em princípio as medidas médicas de tratamento de enfermos terminais só retardam o curso natural da morte e não fazem parte do mandamento de proteger a vida e sim de uma adulteração (verfälschung) da morte.

Nestes casos a interrupção do tratamento está permitida. Com relação à desconexão dos sistemas artificiais de manutenção da vida no âmbito da medicina intensiva (interrupção técnica do tratamento), acredita-se que o decisivo era, do ponto de vista jurídico, determinar se a desconexão constitui uma ação ou omissão. Entretanto, impõe-se a concepção de se pôr fim a um tratamento, assim como a nãorealização do mesmo merece a mesma valoração, desde a perspectiva da eutanásia. Melhor expressando, com as palavras do "Landgericht" de Ravenburg, em sentença dada em 1987. "com independência de que se a conduta do acusado constitui uma omissão ou uma ação, não cometeu um homicídio, ajudou sim a morrer"

\section{Interrupção unilateral do tratamento}

Os tribunais penais não têm se ocupado ainda da questão da interrupção unilateral do tratamento, ou seja, não-consentida pelo paciente (exceto como homicídio privilegiado art. 121, § $1^{\circ}$ : caso de diminuição de pena).

$\mathrm{Na}$ Alemanha se produziu uma disputa entre a esposa de um paciente inconsciente que ingressara na unidade de cuidados intensivos e os médicos que o tratavam. Aquela havia exigido que se desconectasse o respirador necessário para sua sobrevivência ante a falta de perspectivas de êxito do tratamento o que lhe valeu uma denúncia por tentativa de indução ao homicídio ( $\$ 30.1,212$ ST 6/3). Ela, por seu turno, denunciou os médicos por suspeita de lesões corporais causadas pela manutenção da respiração artificial.

c. Eutanásia indireta não se discute que a mitigação de grandes sofrimentos e dores dos enfermos terminais constitui também um dever médico, ainda quando o emprego dos meios inidôneos implique no risco de um encurtamento da vida ou, inclusive, que este seja o seu efeito secundário. 
Não existindo jurisprudência sobre o tema, o médico se encontra em uma situação insatisfatória, já que em virtude das regras gerais do Direito Penal ele atua com dolo eventual de homicídio, isto é, aceitando a produção antecipada da morte. A falta de um limite legal claro entre a mitigação lícita do sofrimento que encurta a vida e a mitigação proibida por via do encurtamento da vida, pode ser responsável de que os médicos mostrem reservas no referente a combater as dores com opiácios, que podem vir a debilitar a respiração em certas circunstâncias.

d. Eutanásia ativa A situação jurídica, neste caso, é inequívoca: punível como delito de homicídio, ainda que o afetado a tenha exigido expressa e seriamente (art. $121 \S 1^{\circ}$ e no Direito alemão $\S 216$ STG/B). Há um objetivo político-social de manter o tabu do homicídio, através de uma proteção penal ilimitada da vida. Na Alemanha, a eutanásia por petição ou solicitada, ou cujo âmbito vai além da eutanásia ativa, se recolhem na estatística penal: quatro condenações em 1987; seis em 1988; três em 1989 e cinco em 1990. (Total = dezoito casos em quatro anos).

\section{e. Suicídio assistido ou auxílio ao suicídio}

Os casos situados no limite entre a participação no suicídio e a eutanásia suscitam importantes problemas jurídicos. A jurisprudência tende a considerar como homício em comissão por omissão por existir a posição de garantidor.

O Tribunal Supremo alemão fundamentou uma absolvição do polêmico médico Julius Hackethal, que deixou cianureto ao alcance de uma enferma de câncer e a instruiu no uso desse veneno.

"Não se pode considerar insustentável, do ponto de vista jurídico, a decisão de consciência do médico que, tentando solucionar o caso extremo de conflito entre a obrigação de proteger a vida $e$ o respeito ao direito à livre determinação da paciente, que em sua opinião sofria lesões graves e irreversíveis, não-optou pela via mais cômoda de ingressá-la na unidade de cuidados intensivos, mas que se baseou no respeito à personalidade da paciente agonizante até que se produziu a morte desta"

O suicídio suscita problemas de delimitação na hora de se distinguir entre o suicídio responsável e o psicopatológico, em que não se pode falar de livre determinação da pessoa. No Direito alemão não se pune expressamente a participação no suicídio, como o nosso. 
Vias à disposição do paciente para preservar seu direito à livre determinação.

É especialmente o medo e um zelo médico excessivo (obstinação terapêutica), em casos de uma enfermidade em fase terminal, o que induz cada vez mais as pessoas a prever, através de uma disposição escrita denominada inexatamente de "testamento do paciente" ou "testamento vital" sem desejo de que se prescinda, devido a seu estado terminal ou ao tipo de enfermidade, de um tratamento adicional.

As objeções que se apresentam a tais decisões existenciais são de que dificilmente são antecipadas pela pessoa sã. Alega-se, também, que a maioria dos formulários utilizados não possuem uma redação juridicamente exata. Ao paciente é preciso assegurar que possa, embora não tenha revogado formalmente sua declaração, efetivar uma mudança de opinião a qualquer tempo.

Toda disposição de um enfermo deve ser examinada segundo o princípio "in dubio pro vita"

É preciso que distingamos da realização de um suicídio, no sentido de um suicidar-se, da recusa à atividade médica que mantém a vida (isto é, deixá-lo à sua sorte). Nos EUA os hospitais concedem, geralmente, a possibilidade de se fazer uso da chamada "ordem de não-ressuscitar" (do not resuscitate orders).

Um outro aspecto peculiar do direito à morte reside na chamada "máquina do suicídio ddr. Ja o ck Kervorkian"

Kervorkian criou um mecanismo a ser acionado por seus pacientes (terminais ou irrecuperáveis), que libera uma dose letal de cloreto de potássio na veia do enfermo, matando-o. Janet Atkins, uma portadora do Mal de Alzheimer, de 54 anos, o usou efetivamente em junho de 1990. A consulta de Janet foi gravada em video tape, mostrando-a segura de sua decisão. Kervorkian foi processado por ter cometido homicídio em primeiro grau (morte com premeditação). O promotor público sustentou que o médico foi a causa primária da morte de Janet. A defesa trouxe a questão de que no Estado de Michigan, a colaboração com o suicídio nãoconstitui crime, desde 1983. O juiz Gerald Mc Mally, da Corte Distrital do Condado de Oakland rejeitou a acusação, sob o fundamento da inexistência ao suicídio.

Há poucos meses Kevorkian foi condenado a pena de dez a 25 anos por matar inúmeras pessoas.

f. Carlos S. Nino em um artigo denominado "Da lo mismo omitir que atuar?" se ocupa da diferença que existe entre o matar e deixar morrer, entre atos e 
omissões. Imaginemos uma máquina que contenha duas crianças: João e Maria. Apertando-se um botão, João será morto, mas Maria não. Caso não se aperte o botão João sobrevive, mas Maria morre (Michael Tooley, Killing and Letting Die).

Será que realmente a ação de se abster intencionalmente de apertar o botão é moralmente preferível a ação de apertá-lo, mesmo que uma pessoa morra?

O Direito, por sua vez, castiga com mais severidade a ação positiva que a omissão. Por quê? Pelas conseqüências diversas quanto à liberdade do indivíduo. Se se castiga a ação A (empurrar uma pessoa no rio, para que se afogue) resta sempre a disposição do indivíduo as restantes ações de um conjunto determinado $\mathrm{B}, \mathrm{C}, \mathrm{D}, \ldots$... Castigando-se a omissão de salvar um indivíduo que está se afogando, só há uma ação possível: lançar-se na água e realizar o salvamento.

Conclusões

1. Não há diferença moral entre a eutanásia ativa e a passiva, entre matar e deixar morrer.

2. A ortotanásia entendida como auxílio médico ao morrer pode ser considerada como causa de exclusão da ilicitude. Melhor seria, porém, que se tratasse de um tipo penal autônomo.

3. Juridicamente, o médico não está obrigado, mas meramente facultado, para aceder ao requerimento do paciente, maior, capaz e que tenha efetivado um "testamento vital" prévio.

4. Supomos que o médico deva coincidir com o enfermo sobre qual é 0 interesse deste.

5. A permissão da ortotanásia, com a álea do erro dos diagnósticos, enseja, não-obstante, o perigo dos abusos. "Médicos levianos, inescrupulosos ou displicentes, ou demasiadamente confiantes na sua previsão de morte, podem deixar-se aliciar pelas insinuações interesseiras de parentes que visam a uma herança, ou a evitar que esta se desfalque com um tratamento dispendioso do enfermo e ser induzidos, ainda que por furtivo influxo do subconsciente, a admitir como realidade o que talvez não passe de errônea suposição de insuperável proximidade da morte e a não-aplicar, ou interromper a aplicação dos recursos distanásicos", Hungria, Nelson. Ortotanásia ou eutanásia por omissão, p. 752).

$\mathrm{Na}$ verdade, todas as várias posições reconduzem, em última análise, àquelas fundamentais e contrapostas concepções do próprio homem, a utilitarista e a 
personalista. Pela concepção utilitarista o homem é considerado como homem-coisa, mera entidade bio-socio-econômica, como homem meio e, portanto, instrumentalizáveis. Pela concepção personalista se afirma, ao contrário, o primado do homem como valor ético em si: do homem-pessoa, do homem-fim, com a categórica proibição de qualquer instrumentalização: "bem pessoa" e "bem comum" não-colidem, mas coincidem, constituindo o respeito da pessoa o próprio fim de toda a sociedade.

São Paulo, setembro de 1999.

Bibliografia

ASÜA, Luiz Jimenez de. Liberdad de amar y derecho a morir. Buenos Aires, Depalma, 1985.

BACON, F História vitae et mortis, 1923, apud: L. J. de Asúa.

BAYOBLG, in: NJW 1987, pp. 294 e ss.

KANT, I. Fundamentos da Metafísica dos Costumes, Porto, Porto Ed., 1995.

PESSINI, Leocir. Morrer com dignidade, São Paulo, Aparecida, 1990.

POLLARD, B. Eutanasia: devemos matar a los enfermos terminales? Madri, A. Temes, 1991

RAVENS BURG, L. G., in: NSTZ 1987, pp. 299 e ss.

SANTOS, Maria Celeste Cordeiro Leite. Transplante de órgãos e eutanásia. Liberdade e responsabilidade. São Paulo, Saraiva, 1992. . Morte encefálica e a lei de transplantes de órgãos. São Paulo, Oliveira Mendes Ed., 1998.

O equilíbrio do pêndulo. A Bioética e a Lei: Implicações MédicoLegais. São Paulo, Icone Ed., 1998.

VILA-CORO, M.D. Introduccion a la biojuridica. Serviço de publicações da Faculdade de Direito Complutense, 1995. 